\title{
EFEkTifitas Fungsi Hutan Kota di Surakarta
}

\author{
Gunung Gambiro, Galing Yudhana, Winny Astuti \\ Program Studi Perencanaan Wilayah Dan Kota \\ Fakultas Teknik \\ Universitas Sebelas Maret, Surakarta \\ email: gambiro.gunung@gmail.com
}

\begin{abstract}
In limited urban forest in developed cities, the existence of the urban forest is very important to maintain the sustainability of the city. In the era of developed city there are still a lot of urban forest functions considered not important. Thus, the potential of urban forest in the Surakarta currently is expected to be maximized its function in order to be effective. The Problem in this research is how effectively the functions of urban forests in Surakarta. With the aim to determine the efficiency of urban forest based on its functions for the survival existence of an existing green open space in Surakarta currently. Thus the effective functions of the urban forest in Surakarta today become crucial, according to the function of ecological, social, economic and aesthetic. Through observation method and questionnaire as well as the calculation of scoring and linkert scale are expected to provide findings in the research of how effectively the functions of urban forests in Surakarta today. Therefore, in this analysis requires identification of the stages characteristic of urban forest areas, analysis urban forest functions, and analysis the effectiveness of urban forest functions. From the analysis of the effectiveness urban forest function, it was found that the effectiveness of urban forest functions in Surakarta was not only seen through the effectiveness of quantity but also the quality of the urban forest itself. The effectiveness of urban forest will run well with the commitment of government and society. This research recommendations in the planning area is to give a good management and maintenance and sustainable development that capable producing urban forest function to be more effective in the quality and quantity.
\end{abstract}

Keywords: Green Open Space, Effectiveness, Urban Forest Functions, Quantity and Quality.

\section{PENDAHULUAN}

Hutan Kota adalah suatu hamparan lahan yang dimana bertumbuh pohon-pohon yang kompak dan tumbuh secara rapat di dalam wilayah perkotaan baik pada tanah negara maupun tanah, yang ditetapkan sebagai Hutan Kota oleh pejabat yang berwenang. Keberadaan Hutan Kota Surakarta termasuk berada di dalam ruang terbuka hijau kota dan memiliki dampak yang lebih terasa untuk kota. Banyak manfaat dan fungsi hutan kota memiliki fungsi utama intrinsik yaitu fungsi ekologis, dan fungsi tambahan ekstrinsik yaitu fungsi arsitektural, sosial, dan fungsi ekonomi. Perencanaan wilayah perkotaan dalam empat fungsi utama di atas ini dapat dikombinasikan sesuai dengan kebutuhan, kepentingan dan keberlanjutan kota (Rustam, 1987). Perkembangan dan perubahan faktor sosial, ekonomi, budaya, ilmu pengetahuan dan lain sebagainya akan mengakibatkan perkembangan dan perubahan lansekap perkotaan (Simonds, 1983).
Salah satu dampak dari kurang optimalnya keberadaan Hutan Kota di Surakarta yaitu tingginya frekuensi banjir dan tanah longsor di perkotaan dewasa ini juga diakibatkan karena terganggunya sistem tata air. Kondisi tersebut secara ekonomi juga dapat menurunkan tingkat produktivitas, dan menurunkan tingkat kesehatan dan tingkat harapan hidup masyarakat. Penyediaan lahan di kota-kota besar maupun kota sedang berkembang di Indonesia dirasakan sangat sulit dan membutuhkan biaya yang cukup besar.

Hutan Kota di perkotaan sangat sulit dilakukan, karena alih fungsi lahan terbuka menjadi lahan terbangun terus terjadi seiring dengan bertambahnya penduduk, dibarengi dengan bertambahnya pengadaan sarana dan sarana perkotaan. Sedangkan efektifitas berasal dari kata efek yang artinya pengaruh yang ditimbulkan oleh sebab, akibat/dampak. Keefektifan sesuatu bisa dilihat dari ketepatgunaan, hasil guna, penunjang tujuan menurut (Dahlan, 1994). 
Berkaitan hal tersebut untuk itu pentingnya mengetahui efektifitasan fungsi Hutan Kota di Kota Surakarta demi eksistensi keberadaan ruang terbuka hijau Surakarta, yang akan berdampak terhadap menciptakan masyarakat yang baik, dan menciptakan lingkungan yang nyaman, kemudian penelitian ini diharap bisa menjadi rujukan.

Tujuan dan manfaat efektifitas fungsi Hutan Kota di Surakarta:

1. Mengetahui efektifitasan Hutan Kota Surakarta berdasarkan fungsinya demi kebertahanan eksistensi ruang terbuka hijau publik yang sudah ada di Kota Surakarta saat ini.

2. Mengetahui karakteristik dan kondisi eksisting Hutan Kota di Surakarta.

3. Mengetahui efektifitas fungsi Hutan Kota di Kota Surakarta.

4. Menciptakan lingkungan yang berkelanjutan serta dengan melibatkan fungsi Hutan Kota dengan baik secara kuantitas dan kualitas.

Kemudian dalam menjabarkan manfaat akademis dan praktis ialah, dalam manfaat akademis yaitu pengayaan keilmuan bagi mahasiswa Perencanaan Wilayah dan Kota tentang sejauh mana efektifitas fungsi Hutan Kota di Kota Surakarta. Penelitian ini bersinggungan dengan bagian perencanaan kota, perencanaan wilayah regional planning dan manajemen pembangunan perkotaan (urban development management) serta keruangan kota.

Sedangkan pada manfaat praktis yaitu pertama dapat memberi rujukan pemerintah atau perencana. Kemudian diharap menjadi temuan awal dan memberi pengetahuan kepada masyarakat tentang manfaat keberadaan Hutan Kota di suatu kota. Sehingga bisa berdampak untuk perkembangan Hutan Kota di Kota Surakarta.

\section{TINJAUAN PUSTAKA}

Tinjauan pustaka merupakan kajian yang dilakukan terhadap berbagai macam teori yang terkait dengan tema penelitian yaitu Efektifitas Fungsi Hutan Kota di Surakarta. Ruang publik juga memiliki arti merupakan suatu wadah yang dapat menampung kegiatan tertentu dari warga lingkungan tersebut baik secara individu atau secara kelompok. Salah satu bentuk ruang publik salah satunya adalah jalan, pedestrian, taman, plaza, pemakaman, lapangan olahraga (Hakim, 1987). Dalam Keputusan Presiden No. 32 Tahun 1990 Tentang Pengelolaan
Kawasan Lindung, Hutan Lindung adalah hutan yang memiliki sifat khas yang mampu memberikan lindungan pada kawasan sekitar sebagai pengatur tata air, pencegah banjir dan erosi serta memelihara kesuburan tanah.

Seperti yang berada didokumen PP no 33 tahun 1970 tentang Perencanaan Hutan pasal 7 ayat 2 , hutan lindung juga merupakan kawasan hutan yang pengelolaannya bertujuan untuk memperoleh fungsi sebesar besarnya terhadap pengaturan tata air, pemeliharaan kesuburan tanah serta pencegahan bencana banjir dan erosi. Hutan Kota adalah sekelompok vegetasi berupa pepohonan dan sejenisnya yang tumbuh di lahan kota, strukturnya menyerupai bentuk hutan alam yang berimplementasi kenyamanan, kesejukan dan suasana yang sehat serta memungkinkan kehidupan satwa (Ramli, 1999).

Hutan selain berfungsi sebagai sarana rekreasi dapat juga menjadi sarana pendidikan, darah penyangga kebutuhan air, mencegah banjir, erosi, melindungi sistem tata air dan sebagai sumber air minum kota yang perlu dilindungi dari segala bentuk pencemaran. Hutan Kota tidak dapat dipisahkan dari manusia baik secara psikologis, emosional, atau dimensional. Manusia berada di dalam ruang, bergerak, menghayati, dan berpikir, juga membuat ruang untuk menciptakan dunianya (Djoko, 1999).

Fungsi hutan kota dibagi menjadi dua, yaitu fungsi ekologis, serta fungsi-fungsi tambahan seperti ekonomi, sosial budaya dan arsitektural (Prihandono, 2009). Bisa juga Hutan Kota kawasan perkotaan berfungsi sebagai pengamanan keberadaan kawasan lindung perkotaan, pengendali pencemaran dan kerusakan tanah, air dan udara, tempat perlindungan dan keanekaragaman hayati, pengendali tata air dan sarana estetika kota Permendagri Nomor 1 Tahun 2007 pasal 3. Berikut di bawah ini adalah penjabaran mengenai variabel, seperti Tabel 1 .

Tabel 1. Variabel Hutan Kota

\begin{tabular}{|l|l|l|l|}
\hline \multicolumn{3}{|l|}{ Variabel Hutan Kota } \\
\hline No. & Teori & Fungsi & Resume \\
\hline 1. & $\begin{array}{l}\text { Dep PU/ } \\
\text { RTH } \\
\text { Perkotaan }\end{array}$ & $\begin{array}{l}\text { Ekologi, } \\
\text { Sosial, } \\
\text { Ekonomi, } \\
\text { Arsitektural }\end{array}$ & $\begin{array}{l}\text { Ekologi, Sosial, } \\
\text { Ekonomi, } \\
\text { Estetika }\end{array}$ \\
\hline 2. & $\begin{array}{l}\text { (Prihandono } \\
\text { 2009). }\end{array}$ & $\begin{array}{l}\text { Ekologi, } \\
\text { Social } \\
\text { budaya, } \\
\text { Ekonomi, } \\
\text { Arsitektural }\end{array}$ \\
& & Ekologi, & \\
\hline 3. & (Sunturo. & \multicolumn{2}{|l}{} \\
\hline
\end{tabular}




\begin{tabular}{|c|c|c|}
\hline & 2007) & $\begin{array}{l}\text { Rekreasi, } \\
\text { Estetika, } \\
\text { Hidrologi, } \\
\text { Kesehatan }\end{array}$ \\
\hline 4. & $\begin{array}{l}\text { (Sukawan } \\
\text { 2012:20) }\end{array}$ & $\begin{array}{l}\text { Ekologi, } \\
\text { Sosial, } \\
\text { Ekonomi, } \\
\text { Estetika }\end{array}$ \\
\hline
\end{tabular}

Fungsi Hutan Kota Surakarta pada kategori ini adalah untuk perlindungan atau pengamanan, sarana dan prasarana misal melindungi kelestarian sumber daya alam, pengaman pejalan kaki atau membatasi perkembangan penggunaan lahan agar fungsi utama tidak teganggu. Pengertian efektifitas adalah suatu keadaan yang menunjukkan tingkat keberhasilan atau kegagalan kegiatan manajemen dalam mencapai tujuan yang ditetapkan (Soetrisno. 2010). Comfort, unsur kenyamanan. Relaxation, kenyaman secara psikologi. Passive and Active engagement, unsur kegiatan yang bersifat aktif maupun pasif. Discovery, berkaitan dengan manfaat yang diperoleh atau pengalaman yang diperoleh setelah mengunjungi ruang publik (Carr, 2003). Untuk itu pembangunan hutan kota sebaiknya melihat karakteristik dan potensi yang ada di hutan kota tersebut.

\section{METODE PENELITIAN}

Metode penelitaian merupakan suatu tinjauan yang dilakukan dengan berbagai teori yang relevan.

\subsection{Ruang Lingkup}

Ruang lingkup wilayah penelitian ini yaitu wilayah Surakarta. Lokasi wilayah studi dari jumlah total hutan kota yaitu 25 lokasi kemudian dikerucutkan atau disimpulkan menjadi 5 tempat Hutan Kota terpilih, lokasi studi diperoleh dari peraturan dan teori terkait Hutan Kota, lokasi dan batas administratif, 5 lokasi penelitian ini didapatkan dari kriteria lokasi sebelumnya, berikut lokasi wilayah studi dijelaskan pada Tabel 2.

Tabel 2. Wilayah Studi Hutan Kota

\begin{tabular}{|l|lr|c|}
\hline No. & Lokasi & Luas $\left(\mathbf{m}^{\mathbf{2}}\right)$ \\
\hline 1. & $\begin{array}{l}\text { Timur taman Makam } \\
\text { Pahlawan } \\
\text { Bhakti }\end{array}$ & 46.040 \\
\hline 2. & \multicolumn{2}{|l|}{ Taman Balekambang } & 33.400 \\
\hline 3. & \multicolumn{2}{|l|}{ Taman Satwa Jurug } & 55.640 \\
\hline 4. & $\begin{array}{l}\text { Taman Makam } \\
\text { Pahlawan } \\
\text { Bhakti }\end{array}$ & 48.000 \\
\hline 5. & Edusuma Park & 50.000 \\
\hline
\end{tabular}

Sumber: Badan Lingkungan Hidup Surakarta, 2015.

\subsection{Metode Analisis}

Penelitian ini menggunakan metode pendekatan deduktif, model pendekatan deduktif umum dan khusus. Jenis penelitian yang digunakan adalah jenis penelitian kuantitatif.

\subsubsection{Metode kuantitatif}

Metode kuantitatif yang merupakan berdasarkan filsafat pasitivisme biasanya digunakan dalam populasi atau sampel tertentu (Sugiyono, 2015), teknik pengumpulan data dilakukan secara rendom, adanya instrument penelitian, dan bersifat statistik, dalam penelitian ini salah satunya dijabarkan dalam skoring terhadap setiap variabel Hutan Kota di Surakarta. Jenis data yang digunakan yaitu jenis data primer dan data sekunder. Populasi dalam penelitian ini adalah melibatkan seluruh masyarakat dikawasan dan pengunjung Hutan Kota. Wawancara dilakukan secara mendalam dan terstruktur untuk memudahkan proses penelitian.

\subsection{Teknik Analisis}

Teknik analisis yang digunakan dalam penelitian ini adalah teknik analisis observasi yang kemudian diskoring dan Kuisioner yang kemudian diukur dengan Sekala Linkert untuk melihat ke efektifitas fungsi Hutan Kota.

\subsection{Variabel Penelitian}

Variabel penelitian menurut Sugiyono (2013) adalah kesimpulan serta hasil kajian yang ditetapkan oleh peneliti dari hasil dari mempelajari segala informasi-informasi yang telah dicari dan dikumpulkan yang mempunyai variasi dan nilai tertentu. Variabel dan indikator penelitian dapat dilihat pada Tabel 3.

Tabel 3. Variabel dan Indikator Penelitian

\begin{tabular}{|l|l|l|}
\hline Variabel & $\begin{array}{l}\text { Sub } \\
\text { Variabel }\end{array}$ & Indikator \\
\hline Ekologi & $\begin{array}{l}\text { Berfungsiny } \\
\text { a resapan air } \\
\text { ditunjang } \\
\text { dengan } \\
\text { biopori }\end{array}$ & $\begin{array}{l}\text { Banyaknya pepohonan } \\
\text { dikawasan RTH Publik } \\
\text { serta terdapatnya biopori }\end{array}$ \\
\cline { 3 - 3 } & $\begin{array}{l}\text { Setidaknya ada } \\
\text { pepohonan atau biopori } \\
\text { saja }\end{array}$ \\
\cline { 3 - 3 } & $\begin{array}{l}\text { Tidak adanya } \\
\text { pepohonan, jika hanya } \\
\text { padang rumput }\end{array}$ \\
\cline { 2 - 3 } & $\begin{array}{l}\text { Penahan dan } \\
\text { Penyaring } \\
\text { Partikel } \\
\text { Padat dari }\end{array}$ & $\begin{array}{l}\text { Jika } \\
\text { pepohonan besar yang } \\
\text { bertitik diperbatasan } \\
\text { serta di tengah kawasan } \\
\text { RTH }\end{array}$ \\
\hline
\end{tabular}


Gunung Gambiro, Galing Yudana, Winny Astuti, Efektifitas Fungsi...

\begin{tabular}{|c|c|c|}
\hline & $\begin{array}{l}\text { Penapis } \\
\text { Cahaya } \\
\text { Silau }\end{array}$ & $\begin{array}{lr}\text { Jika } & \text { keberadaan } \\
\text { pepohonan } & \text { secara acak } \\
\text { di lokasi RTH } & \\
\end{array}$ \\
\hline & & $\begin{array}{l}\text { Jika tidak memiliki } \\
\text { kedua karakteristik RTH } \\
\text { yg teduh }\end{array}$ \\
\hline \multirow[t]{9}{*}{ Sosial } & \multirow[t]{3}{*}{ Rekreasi } & 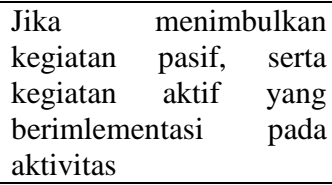 \\
\hline & & $\begin{array}{l}\text { Jika hanya terdapat salah } \\
\text { satu antara kegiatan } \\
\text { pasif atau aktif }\end{array}$ \\
\hline & & $\begin{array}{lll}\text { Jika tidak } & \text { terdapat } \\
\text { kegiatan aktif } & \text { maupun } \\
\text { pasif } & & \\
\end{array}$ \\
\hline & \multirow[t]{3}{*}{$\begin{array}{l}\text { Pendidikan } \\
\text { lingkungan }\end{array}$} & $\begin{array}{l}\text { Jika adanya unsur } \\
\text { edukasi serta sarana } \\
\text { berekspresi warga }\end{array}$ \\
\hline & & $\begin{array}{l}\text { Jika ada salah satu } \\
\text { antara unsur edukasi } \\
\text { atau wadah ekspresi } \\
\text { warga Kota }\end{array}$ \\
\hline & & $\begin{array}{l}\text { Jika tidak terdapat } \\
\text { kegiatan edukasi dan } \\
\text { ruang ekspresi warga }\end{array}$ \\
\hline & \multirow[t]{3}{*}{$\begin{array}{l}\text { Interaksi } \\
\text { social }\end{array}$} & $\begin{array}{l}\text { Jika terdapat lebih dari } \\
\text { satu komunitas yang } \\
\text { sering berkegiatan }\end{array}$ \\
\hline & & $\begin{array}{lrr}\begin{array}{l}\text { Jika hanya ada } \\
\text { komunitas }\end{array} & \text { yang } \\
\text { beraktifitas } & & \\
\end{array}$ \\
\hline & & $\begin{array}{l}\text { Jika tidak ada komunitas } \\
\text { yang melakukan } \\
\text { aktivitas }\end{array}$ \\
\hline \multirow[t]{6}{*}{ Ekonomi } & \multirow[t]{3}{*}{ Pendapatan } & $\begin{array}{lr}\text { Jika kegiatan usaha } \\
\text { tersebut menghasilkan } \\
\text { keuntungan } \\
\text { pedagang } & \text { bagi } \\
\text { pendapatan kota } & \text { dan } \\
\end{array}$ \\
\hline & & $\begin{array}{lr}\text { Jika hanya } & \text { kegiatan } \\
\text { usaha } & \text { tersebut } \\
\text { menghasilkan } & \\
\text { keuntungan } & \text { bagi } \\
\text { pedagang } & \\
\end{array}$ \\
\hline & & $\begin{array}{lr}\text { Jika tidak adanya } \\
\text { keuntungan } & \text { bagi } \\
\text { pedagang dan kota } & \end{array}$ \\
\hline & \multirow{3}{*}{$\begin{array}{l}\text { Sebagai } \\
\text { tempat } \\
\text { berdagang }\end{array}$} & $\begin{array}{l}\text { Jika terdapat lebih dari } 1 \\
\text { jenis usaha perdagangan }\end{array}$ \\
\hline & & $\begin{array}{l}\text { Jika terdapat } 1 \text { kegiatan } \\
\text { usaha perdagangan }\end{array}$ \\
\hline & & $\begin{array}{lc}\text { Jika tidak } & \text { terdapat } \\
\text { kegiatan usaha } & \\
\end{array}$ \\
\hline \multirow[t]{4}{*}{ Estetika } & \multirow[t]{3}{*}{$\begin{array}{l}\text { Sebagai } \\
\text { penghubung } \\
\text { atau } \\
\text { pembatas }\end{array}$} & $\begin{array}{l}\text { Jika tanaman tinggi, } \\
\text { bermasa daun rapat, } \\
\text { serta jarak tanaman } \\
\text { rapat. }\end{array}$ \\
\hline & & $\begin{array}{l}\text { Jika hanya ada tanaman } \\
\text { berdaun rapat }\end{array}$ \\
\hline & & $\begin{array}{l}\text { Jika padang rumput atau } \\
\text { tanah kosong }\end{array}$ \\
\hline & $\begin{array}{l}\text { Identitas } \\
\text { Kota }\end{array}$ & $\begin{array}{lr}\text { Jika terdapat lebih dari } 1 \\
\text { landmark } & \text { yang } \\
\text { berdampak } & \text { terhadap } \\
\text { keindahan } & \end{array}$ \\
\hline
\end{tabular}

\begin{tabular}{|l|l|l|}
\hline & $\begin{array}{l}\text { Jika hanya terdapat satu } \\
\text { landmark }\end{array}$ \\
& $\begin{array}{l}\text { Jika tidak terdapat } \\
\text { landmark }\end{array}$ \\
\hline
\end{tabular}

\section{HASIL PENELITIAN}

Identifikasi fungsi Hutan Kota Surakarta seperti yang ditujukan hasil skoring analisis sebelumnya, diketahui bahwa terdapat empat fungsi dalam menunjang hutan kota yaitu, ekologi, sosial, ekonomi, dan estetika. Masingmasing studi kasus memiliki penilaian atau temuan yang mewakili keadaan dalam Efektifitas Fungsi Hutan Kota di Kota Surakarta. Dalam kesesuaian efektifitas tentunya besaran presentase target yang dicapai makin besar juga efektifitasnya. Efektifitas Hutan Kota di Surakarta diukur dari segi target baik itu kualitas, kuantitas dan waktu telah tercapai. Efektifitas yang bertumpu pada pendekatan tujuan diartikan sebagai pencapaian sasaran yang telah disepakati atas usaha bersama.

Dari segi efektifitas fungsi ekologi melibatkan dua metode yaitu observasi dan kuisioner, kemudian dari metode tersebut diolah dengan cara pembobotan atau skoring untuk observasi serta kuisioner dan sekala Linkert untuk metode kuisioner. Dari temuan yang didapatkan dalam analisis sebelumnya fungsi ekologi Hutan Kota Surakarta bisa dinilai efektif. Ekologis mempunyai fungsi, yaitu sebagai penjaga kualitas lingkungan kota (Sunturo, 2007). Efektifitas hutan kota dalam ekologi bisa dinilai dari segi comfort, unsur kenyamanan seperti keberadaan pepohonan, sumur resapan atau biopori mampu mempercepat penyerapan air di suatu kawasan (Carr, 2003).

Hasil analisis ditemukan beberapa temuan saat observasi terkait kualitas penunjang Hutan Kota terkait ekologis ini yang kurang terawat. Biopori yang masih tidak terawat terlihat masih banyak, sehingga daya resap air yang ada di kawasan Hutan Kota di Surakarta kurang maksimal, akan tetapi tanaman yang ada sudah cukup rindang dan rapat di kawasan Hutan Kota, hanya saja perawatan seperti diberi pupuk dan pembersihan tanaman dari benalu masih jarang dilakukan. Kuantitas ekologi Hutan Kota di Surakarta sudah cukup baik akan tetapi kualitasnya masih harus ditingkatkan seiring dengan makin banyaknya pencemaran udara serta volume curah hujan yang tidak menentu saat musim hujan membuat Hutan Kota yang 
ada di Surakarta harus dalam kondisi yang baik.

Aspek fungis sosial dilakukan dengan metode yang sama yaitu observasi serta kuisioner dan sekala Linkert. Dari temuan yang didapatkan dalam menggunakan analisis sebelumnya efektifitas fungsi sosial Hutan Kota di Kota Surakarta bisa dikatakan cukup efektif hingga sangat efektif. Dalam kajian terlihat bahwa fungsi hutan kota sebagai wadah interaksi sosial berjalan baik di Surakarta. Dalam efektifitas fungsi sosial berkaitan dengan comfort, unsur kenyamanan dan kegiatan passive active engagement, unsur kegiatan yang bersifat aktif maupun pasif (Carr, 2003). Dari segi fasilitas penunjang menurut observasi juga bisa dinilai baik. Peremajaan dan pengelolaan yang perlu ditingkatkan agar Hutan Kota yang ada di Surakarta tetap bisa berkelanjutan serta bisa memberi ruang masyarakat Surakata untuk berinteraksi dengan nyaman dan menimbulkan interkasi sosial yang tinggi.

Terkait efektifitas fungsi ekonomi Hutan Kota di Surakarta dilakukan dengan metode analisis yang sama pada fungsi sebelumnya. Efektifitas suatu ukuran jauh mana target (kualitas, kuantitas dan waktu) telah tercapai. Besar presentase target yang dicapai makin besar efektifitasnya (Hidayat, 1986). Dalam fungsi ekonomi ini kefektifan bisa dilihat dari segi kegiatan passive active engagement, unsur kegiatan yang bersifat aktif maupun pasif (Carr, 2003).

Dari analisis sebelumnya ditemukan bahwa fungsi ekonomi tidak berjalan dengan baik kuantitas yang ada di Hutan Kota Surakarta juga belum terpenuhi dengan baik belum adanya pengelolaan pedagang kaki lima yang baik serta sistem retribusi atau bagi hasil keuntungan yang jelas antara pedagang pengelola hutan serta pemerintah, semua berjalan masing-masing, sehingga dalam analisis sebelumnya juga terjadi perbedaan yang signifikan dengan fungsi yang lain. Ada beberapa Hutan Kota di Surakarta yang sangat efektif akan tetapi masih banyak pula yang tidak efektif bahkan terkesan terbengkalai sehingga nilai ekonomi dalam hutan kota tersebut tidak berjalan dengan baik.

Jika melihat dari fungsi estetika terkait dengan efektifitas dalam Hutan KotaSurakarta ini dilakukan dengan metode yang sama terhadap fungsi lainya yaitu ekologi, sosial, dan ekonomi. Dari kajian yang dilakukan dengan analisis sebelumnya fungsi estetika didapatkan berada pada level efektif hingga sangat efektif. Sama seperti fungsi yang ada sebenarnya dalam kuantitas pengadaanya sudah cukup memadai akan tetapi menurut observasi di lapangan kerap ditemui fungsi estetika tidak berjalan dengan baik.

Untuk mewujudkan efektifitas fungsi estetika hutan kota harus memenuhi unsur relaxation, kenyaman secara psikologi (Carr, 2003). Kebanyakan pengunjung merasakan kenyamanan dalam pemikiran atau relaks, akan tetapi permasalahan fungsi estetika kebanyakan bermuara dari minimnya anggaran pemeliharaan dan kesadaran masyarakat unutk menjaga tanaman-tanaman yang bernilai estetika serta bangunan atau landmark yang menjadi citra lokasi tersebut. Pencapaian efektif bisa dikatakan jika sudah mencapai tujuan, dalam pencapaian tujuan itu fungsi hutan kota yaitu ekologi, sosial, ekonomi dan estetika dirasa masih perlu pendampingan baik masyarakat maupun pemerintah.

Perkembanganya melihat kesadaran masyarakat yang rendah terhadap pemeliharaan fasilitas publik keadaan Hutan Kota yang ada saat ini bisa semakin terus menurun kualitasnya. Bahkan bukan tidak mungkin Hutan Kota di Surakarta yang ada jika tidak dikawal dengan baik oleh masyarakat dan pemerintah akan menjadi lahan siap bangun karena permintaan lahan kosong perkotaan yang semakin sulit didapat. Tolak ukur efektifitas fungsi Hutan Kota bisa dilihat dari comfort, relaxation, passive and active engagement, discovery (Carr, 2003). Efektifitas yaitu seberapa besar tingkat kelekatan output yang dicapai dengan output yang diharapkan dari sejumlah input (Prasetyo, 1984). Dalam perkembanganya Hutan Kota yang ada saat ini masih bisa lebih efektif jika pemerintah bisa serius menangani kebutuhan fungsi Hutan Kota di Surakarta serta peran masyarakat sebagai pengawas dan pemelihara hutan kota tersebut. Dari hasil di atas berikut adalah tabel observasi yang kemudian dengan scoring, dapat dilihat dalam Tabel 4. berikut.

Tabel 4. Skoring Observasi Fungsi Hutan Kota

\begin{tabular}{|l|l|l|l|}
\hline \multirow{2}{*}{ No. } & Observasi & \multicolumn{2}{|c|}{} \\
\cline { 2 - 3 } & Hutan Kota & Ekologi & Keterangan \\
\hline 1. & $\begin{array}{l}\text { Taman Makam } \\
\text { Pahlawan }\end{array}$ & 6 & \\
\hline 2. & Edu Park & 6 & \\
\hline 3. & Kebun Binatang & 5 & \\
\hline
\end{tabular}


Gunung Gambiro, Galing Yudana, Winny Astuti, Efektifitas Fungsi...

\begin{tabular}{|c|c|c|c|}
\hline & Jurug & \multirow[b]{2}{*}{6} & \multirow{4}{*}{ Sangat Efektif } \\
\hline 4. & $\begin{array}{l}\text { Taman } \\
\text { Balekambang }\end{array}$ & & \\
\hline \multirow[t]{2}{*}{5.} & $\begin{array}{ll}\text { Timur Taman } \\
\text { Makam Pahlawan }\end{array}$ & 6 & \\
\hline & Total & 29 & \\
\hline & Hutan Kota & Sosial & Keteranoan \\
\hline 1. & $\begin{array}{l}\text { Taman Makam } \\
\text { Pahlawan }\end{array}$ & 6 & \\
\hline 2. & Edu Park & 3 & \\
\hline 3. & $\begin{array}{l}\text { Kebun Binatang } \\
\text { Jurug }\end{array}$ & 6 & \\
\hline 4. & $\begin{array}{l}\text { Taman } \\
\text { Balekambang }\end{array}$ & 6 & \\
\hline 5. & $\begin{array}{l}\text { Timur Taman } \\
\text { Makam Pahlawan }\end{array}$ & 4 & \\
\hline & Total & 25 & Sangat Efektif \\
\hline & Hutan Kota & Ekonomi & Keterangan \\
\hline 1. & $\begin{array}{l}\text { Taman Makam } \\
\text { Pahlawan }\end{array}$ & 4 & \\
\hline 2. & Edu Park & 6 & \\
\hline 3. & $\begin{array}{l}\text { Kebun Binatang } \\
\text { Jurug }\end{array}$ & 6 & \\
\hline 4. & $\begin{array}{l}\text { Taman } \\
\text { Balekambang }\end{array}$ & 6 & \\
\hline 5. & $\begin{array}{lr}\text { Timur Taman } \\
\text { Makam Pahlawan }\end{array}$ & 2 & \\
\hline & Total & 24 & Efektif \\
\hline & & & \\
\hline & Hutan Kota & Estetika & Keterangan \\
\hline 1. & $\begin{array}{ll}\text { Taman } & \text { Makam } \\
\text { Pahlawan } & \\
\end{array}$ & 6 & \\
\hline 2. & Edu Park & 6 & \\
\hline 3. & $\begin{array}{l}\text { Kebun Binatang } \\
\text { Jurug }\end{array}$ & 6 & \\
\hline 4. & $\begin{array}{l}\text { Taman } \\
\text { Balekambang }\end{array}$ & 6 & \\
\hline 5. & $\begin{array}{lr}\text { Timur } & \text { Taman } \\
\text { Makam Pahlawan }\end{array}$ & 5 & \\
\hline & Total & 29 & Sangat Efektif \\
\hline
\end{tabular}

Dari hasil analisis observasi dari Tabel 4. kemudian akan diproses dengan hasil analisis kuisioner. Tahapan berikutnya yaitu mengabungkan kusioner dengan observasi, kemudian hasil analisis kuisioner dapat dilihat dalam Tabel 5. berikut.

Tabel 5. Kuisioner Fungsi Hutan Kota

\begin{tabular}{|l|l|l|}
\hline Ekologi & Total Skor & Presentasi Nilai \\
\hline Taman Makam Pahlawan & 125 & Sangat Efektif \\
\hline Edu Park & 145 & Sangat Efektif \\
\hline Kebun Binatang Jurug & 148 & Sangat Efektif \\
\hline Taman Balekambang & 149 & Sangat Efektif \\
\hline $\begin{array}{l}\text { Timur Taman Makam } \\
\text { Pahlawan }\end{array}$ & 94 & Efektif \\
\hline Sosial & Total Skor & Presentasi Nilai \\
\hline Taman Makam Pahlawan & 114 & Sangat Efektif \\
\hline Edu Park & 142 & Sangat Efektif \\
\hline Kebun Binatang Jurug & 149 & Sangat Efektif \\
\hline Taman Balekambang & 149 & Sangat Efektif \\
\hline Timur Taman Makam & 76 & Cukup Efektif \\
\hline
\end{tabular}

\begin{tabular}{|l|l|l|}
\hline Pahlawan & & \\
\hline Ekonomi & Total Skor & Presentasi Nilai \\
\hline Taman Makam Pahlawan & 59 & Sangat Efektif \\
\hline Edu Park & 111 & Sangat Efektif \\
\hline Kebun Binatang Jurug & 126 & Sangat Efektif \\
\hline Taman Balekambang & 140 & Sangat Efektif \\
\hline $\begin{array}{l}\text { Timur Taman Makam } \\
\text { Pahlawan }\end{array}$ & 38 & Tidak Efektif \\
\hline Estetika & Total Skor & Presentasi Nilai \\
\hline Taman Makam Pahlawan & 117 & Sangat Efektif \\
\hline Edu Park & 121 & Sangat Efektif \\
\hline Kebun Binatang Jurug & 137 & Sangat Efektif \\
\hline Taman Balekambang & 147 & Sangat Efektif \\
\hline $\begin{array}{l}\text { Timur Taman Makam } \\
\text { Pahlawan }\end{array}$ & 76 & Cukup Efektif \\
\hline
\end{tabular}

Dari hasil Tabel 5. dengan analisis scoring dan sekala Linkert kemudian disimpulkan, berdasarkan hasil skoring dari observasi dan kuisioner sebelumnya dapat dilihat dalam Tabel 6 . berikut.

Tabel 6. Efektifitas Fungsi Hutan Kota

\begin{tabular}{|l|l|l|l|}
\hline Fungsi & $\begin{array}{l}\text { Observasi \& } \\
\text { Kuisioner }\end{array}$ & Nilai & Nilai \\
\hline \multirow{2}{*}{ Ekologi } & Sangat Efektif & 3 & \multirow{2}{*}{ Sangat Efektif } \\
\cline { 2 - 4 } & Sangat Efektif & 3 & \\
\hline \multirow{2}{*}{ Soasial } & Sangat Efektif & 3 & \multirow{2}{*}{ Sangat Efektif } \\
\cline { 2 - 4 } & Sangat Efektif & 3 & \multirow{2}{*}{ Efektif } \\
\hline Ekonomi & Efektif & 2 & \multirow{2}{*}{ Sangat Efektif } \\
\cline { 2 - 4 } & Efektif & 2 & \\
\hline Estetika & Sangat Efektif & 3 & \\
\cline { 2 - 3 } & Sangat Efektif & 3 & \multicolumn{2}{|c}{} \\
\hline
\end{tabular}

\section{KESIMPULAN}

Secara keseluruhan tingkat keefektifan suatu Hutan Kota di Surakarta berdasarkan fungsi rata-rata bisa dicapai jika ada pengelolaan management yang baik serta kesinergian antara pemerintah dan masyarakat Surakarta itu sendiri. Dilihat dari sasaran di awal penelitian, mengidentifikasi karakteristik dan kondisi eksisting Hutan Kota di Surakarta yang kemudian diulas melalui fakta-fakta di lapangan serta dijabarkan dalam setiap lokasi penelitian. Proses analisisnya terlihat Hutan Kota di Surakarta yang ada saat ini semuanya berjalan secara masing-masing, kemudian yang memberi dampak hutan kota yang yang ada saat ini ada yang sangat terpelihara namun ada juga yang sangat tidak terpelihara atau terkesan terbengkalai.

Kesimpulan secara keseluruhan yaitu semua Hutan Kota di Surakarta yang ada saat ini berkembang secara masing-masing sesuai karakteristik Hutan Kota di Surakarta, kemudian yang memberi dampak hutan kota yang ada saat ini sangat terpelihara namun ada juga yang sangat tidak terpelihara atau terkesan terbengkalai. Kemudian Hutan Kota 
yang ada saat ini dilihat dari analisis dan data memang menunjukan keefektifan secara kuantitas atau efektif dalam pengadaan fasilitas -fasilitas yang ada dalam menunjang fungsi Hutan Kota itu sendiri, akan tetapi jika dari kualitas atau kondisi yang ada fungsifungsi Hutan Kota di Surakarta sejauh ini berjalan kurang efektif. Jika Hutan Kota di Surakarta yang ada saat ini dinilai efektif secara menyeluruh, sebaiknya ada komitmen yang berkelanjutan dari pemerintah bahwa Surakarta harus mampu menjadi kota hijau. Jika sudah memiliki komitmen yang kuat dari pemerintah dan masyarakat. Pembangunan dan pemeliharaan dibarengi dengan pengawasan agar rencana yang dibangun dari awal akan terus berkelanjutan.

\section{REFERENSI}

Badan Lingkungan Hidup Surakarta, 2015. Penelitian Penyusunan Dokumen Peta Tutupan Vegetasi Dan Ruang Terbuka Hijau Publik Kota Surakarta.

Carr. 2003. Ruang Terbuka Hijau Publik. Kerangka Ruang Publik.

Dahlan. 1994. Pengertian Efektif. Jakarta: Gramedia.

Djoko, 1999. Pengertian Hutan Kota. Jurnal Universitas Diponegoro. Semarang.

Hakim. 1987. Ruang publik / wordpress.com.

Hidayat. 1986. Mengukur Efektifitas. Bandung.

Keppres No 32 Tahun 1990 (Kwasan lindung dan pertanahan).

Pemendagri No.1 Tahun 2007 dan PermenPU 05/PRT/M2008 (Jenis RTH).

PP no 33 tahun 1970 pasal 7 ayat 2 (Perencanaan Hutan).

Prihandono. 2009. Fungsi Hutan Kota. Program Pasca Sarjana Universitas Diponegoro. Semarang.
Prasetyo. 1984. Pengertian Efektifitas. Jakarta: Kompas Media.

Ramli. 1999. Hutan Kota. Jakarta : Gramedia. Rustam. 1987. Ruang Terbuka Hijau. Jakarta.

Simonds. 1983. Faktor perubahan lahan. Jakarta: Media Pustaka.

Sugiyono. 2015. Analisis Kuantitatif. Jakarta : Gramedia.

Sugiyono. 2013. Variabel Penelitan. Jakarta: Gramedia Groub.

Sunturo. 2007. Fungsi Ekologi Hutan Kota.

Soetrisno. 2010. Pengertian Efektifitas Bahasa. Jakarta: Prenadamedia Groub. 


\section{LAMPIRAN}

Tabel 6. Lokasi Hutan Kota

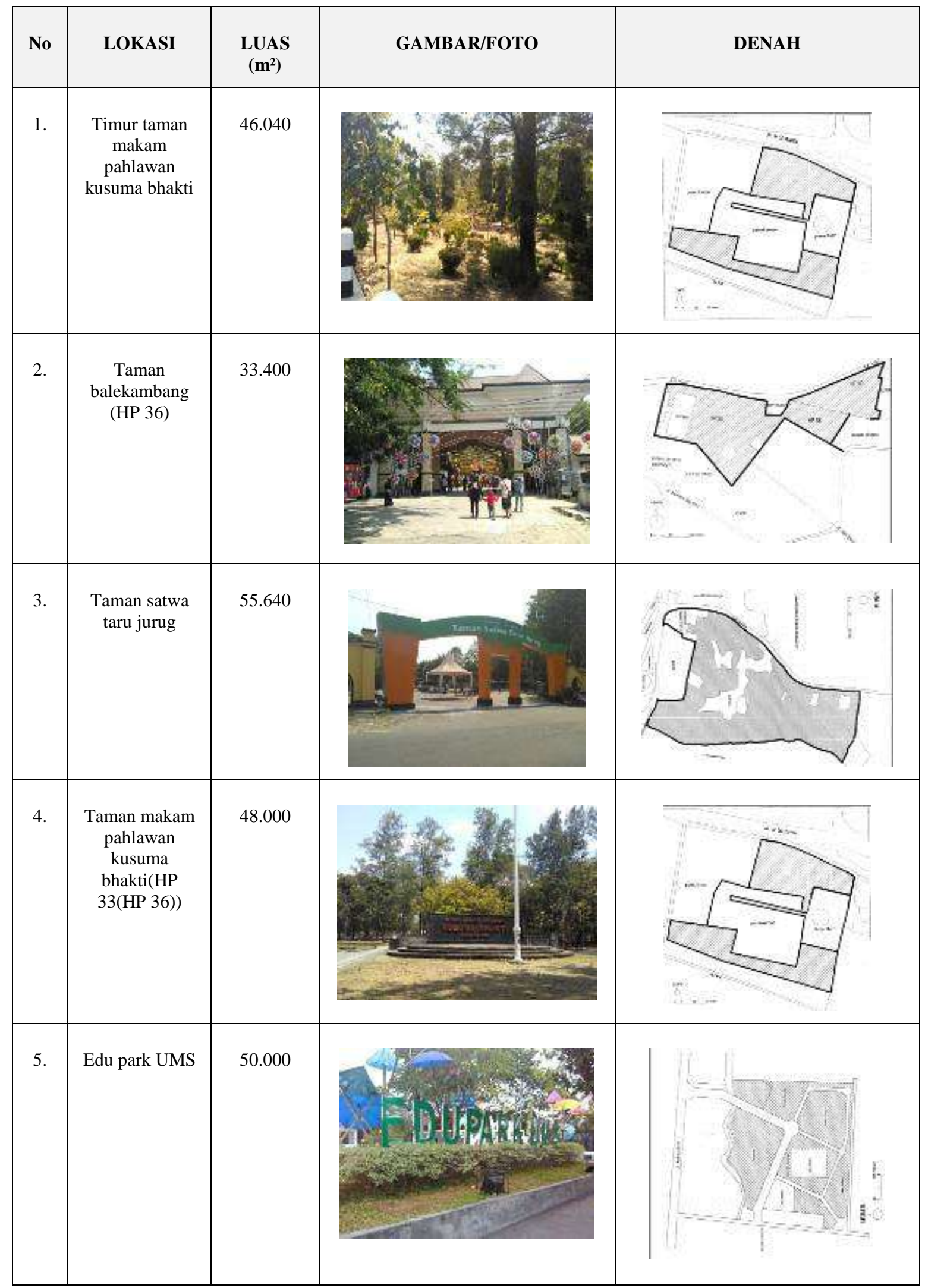

